\title{
A Study on the GHGs Emission Reduction Effect in Winter Depending on Adopting CHP for University Building in Korea
}

\author{
Byeong-Uk, An ${ }^{1}$, Won-Hwa, Hong ${ }^{2, a}$, Ji-Ae Lee ${ }^{3}$ and Youn-Kyu Seo ${ }^{4}$ \\ ${ }^{1}$ School of Architecture, Civil, Environmental and Energy Eng., Kyungpook National University, Korea \\ 2 School of Architecture \& Architectural Eng., Kyungpook National University, Korea \\ ${ }^{3}$ School of Architecture, Civil, Environmental and Energy Eng., Kyungpook National University, Korea \\ ${ }^{4}$ School of Architecture, Civil, Environmental and Energy Eng., Kyungpook National University, Korea
}

\begin{abstract}
As recently the increase in greenhouse gases emission is a serious global concern, international environmental regulations are strengthened and Korea is implementing the relevant regulations also. Since college buildings are clustered in a certain area, they are classified as an energy glutton building group, in which a considerable amount of GHGs emission occurs. In this regard, this research investigated reductions of GHGs emission in winter according to heating load sharing rates when adopting gas turbine CHP for college buildings. As a result of the research, when the heating load sharing rate of CHP is $90 \%$, the reduced amount is the largest at $3,727 \mathrm{tCO}_{2}$ eq, which is a $14 \%$ decrease.
\end{abstract}

\section{Introduction}

Amid an increase in greenhouse gas emission and the acceleration of global warming, the world has been making various efforts to strengthen environmental regulations including Kyoto Protocol and UNFFCCC and also the importance of cutting down energy consumption and GHGs emission are growing.

In 2008, Korea, where the energy dependency on overseas countries is high and energy consumption and GHGs emission are considerable, presented low carbon, green growth as a new paradigm for national progress, and since 2010, the Korean government has been carrying out Management of Target for GHGs \& Energy to decrease by $30 \%$ of GHGs forecast emission of 2020 . Out of total energy consumption in Korea, building sector takes up $16.6 \%$ and is greatly affected by the residents' life style and patterns, so it is expected to achieve a considerable amount of decrease in GHGs emission in this sector. Specifically, college buildings, which are clustered in a certain area, are classified as an energy glutton building group, and they have been changing to high-energy facilities as the educational environment is evolving. Therefore, reduction of GHGs emission must be achieved in the building sector.

With Management of Target for GHGs \& Energy, energy consumption and GHGs emission have decreased but satisfaction of occupancy became low as much as the former decreased. Thus, supplementary energy source that can increase energy supply while reducing GHGs emission. To this end, this research aims to study the effect of CHP (Combined Heat \& Power) installed in college buildings on GHGs emission.

\footnotetext{
${ }^{a}$ Corresponding author: hongwh@knu.ac.kr
}

\section{Overview of subject buildings and calculation of GHGs emission}

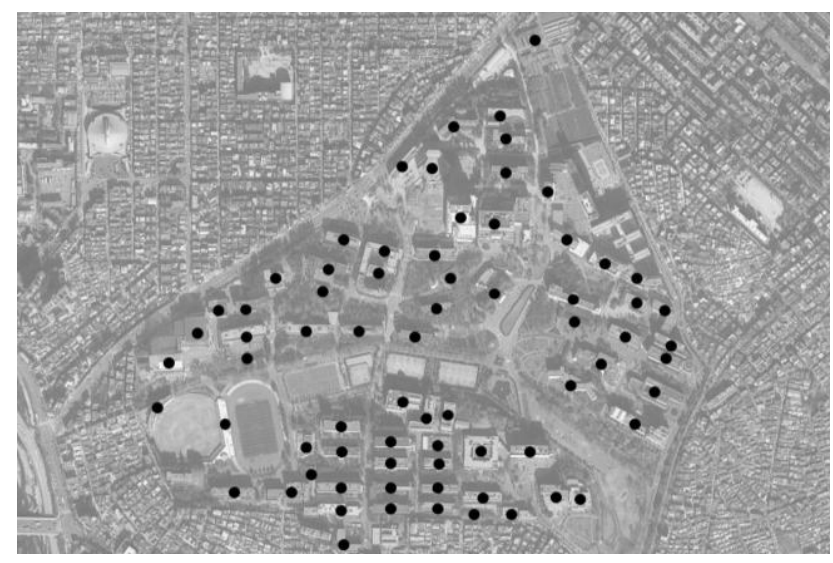

Figure 1. Research subject

Table 1. Overview of research subject

\begin{tabular}{|c|c|c|c|c|}
\hline & \multicolumn{4}{|c|}{ Details } \\
\hline \multirow{3}{*}{ Total area } & \multicolumn{2}{|c|}{ Lot area $\left[\mathrm{m}^{2}\right]$} & \multicolumn{2}{|c|}{828,563} \\
\hline & \multicolumn{2}{|c|}{ Building area $\left[\mathrm{m}^{2}\right]$} & \multicolumn{2}{|c|}{135,503} \\
\hline & \multicolumn{2}{|c|}{ Gross floor area $\left[\mathrm{m}^{2}\right]$} & \multicolumn{2}{|c|}{504,725} \\
\hline \multirow{2}{*}{$\begin{array}{l}\text { Number of } \\
\text { occupancy }\end{array}$} & Student & $\begin{array}{l}\text { Grad. } \\
\text { Student }\end{array}$ & Faculty & Total \\
\hline & 20,051 & 6,324 & 3,279 & 29,654 \\
\hline
\end{tabular}

Among universities implementing Management of Target for GHGs \& Energy, K University located in Daegu was 
selected as a research subject. Figure 1 shows the 72 research subject buildings of $\mathrm{K}$ University. As collage buildings can be used for various purposes, this research specified education and research facility, administration facility, gymnasium, and dormitory as research subject buildings to be analyzed. $99.7 \%$ of energy sources of $\mathrm{K}$ University were electricity and city gas (LNG), so GHGs emission were calculated for the two energy sources. Table 1 shows the area and number of occupancy of $\mathrm{K}$ University.

Figure 2 shows the annual energy consumption and GHGs emission of K University. After Management of Target for GHGs \& Energy implemented since 2010, the energy consumption and GHGs emission tend to decreased slightly. But consumption and emission are still high.

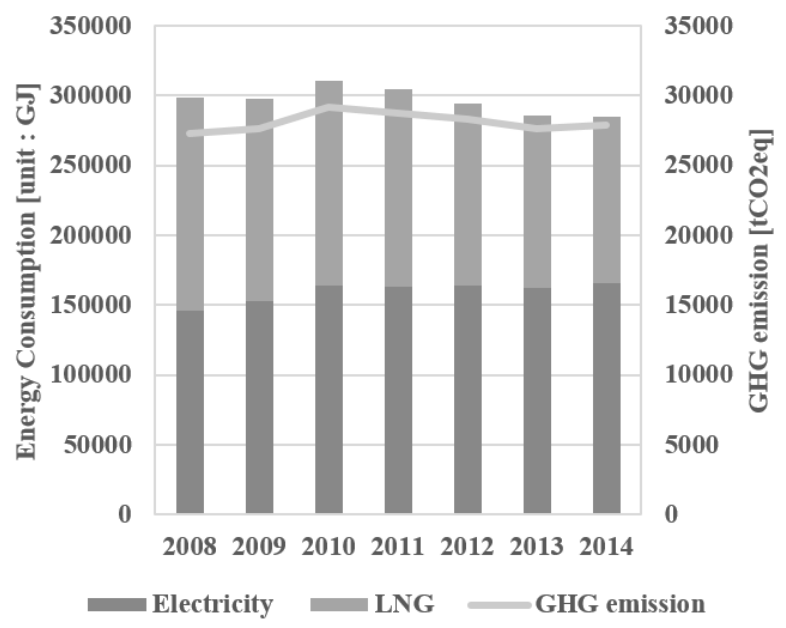

Figure 2. Annual energy consumption and GHGs emission of K University

Table 2. Annual average of energy consumption and GHGs

\begin{tabular}{|l|r|r|l|}
\hline & Electricity & \multicolumn{1}{c|}{ LNG } & Total \\
\hline $\begin{array}{l}\text { Energy } \\
\text { Consumption } \\
\text { [GJ/year] }\end{array}$ & 165,375 & 134,110 & 299,485 \\
\hline $\begin{array}{l}\text { GHGs emission } \\
{\left[\mathrm{tCO}_{2} \text { eq/year }\right]}\end{array}$ & 21,122 & 7,524 & 28,646 \\
\hline
\end{tabular}

Table 2 shows the annual average of energy consumption and GHGs emission of K University. The annual electricity and LNG consumption of K University are $165,375 \mathrm{GJ}$ and $134,110 \mathrm{GJ}$ respectively. Thus the annual total energy consumption of $\mathrm{K}$ University is a total of $299,485 \mathrm{GJ}$, out of which energy consumption in winter is 176,339GJ and annual GHGs emission are $28,646 \mathrm{tCO}_{2} \mathrm{eq}$, out of which GHGs emission in winter is $16,019 \mathrm{tCO}_{2}$ eq.

Figure 3 shows energy consumption and GHGs emission on a monthly basis. Energy consumption and GHGs emission are usually high in winter, which takes up a large portion of total emission. In this research, to reduce GHGs emission in winter, gas turbine CHP was assumed to be installed in the collage buildings and accordingly GHGs emission was calculated.

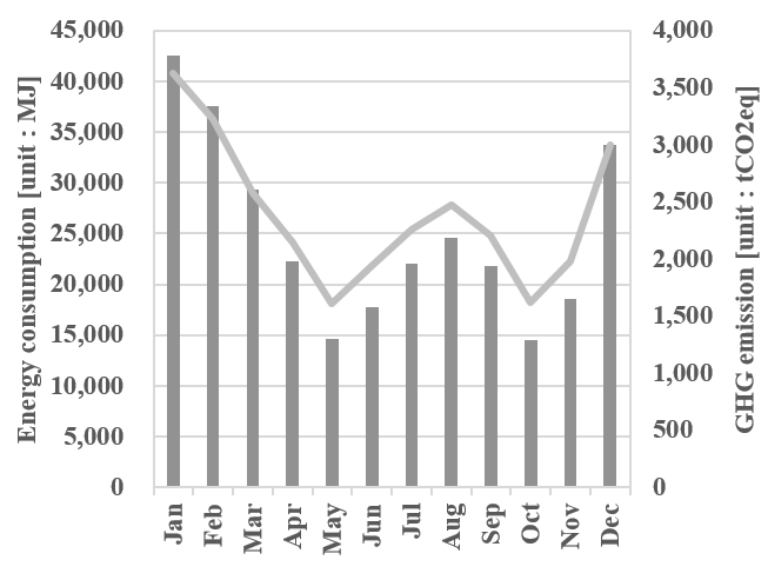

Energy Consumption $\longrightarrow$ GHG emission

Figure 3. Energy consumption and GHGs emission per month

To calculate GHGs emission, the national GHGs emission factors which are notified by the Ministry of Environment were used. By dividing into electricity and LNG, the below equations were used for calculation. GHGs emission calculation formulas are as follows. \{(1) and (2) are the equations for electricity and LNG, respectively\}

$$
\begin{aligned}
& E_{e}=\sum\left(C_{e} * E_{f e} * G_{w}\right) \\
& E_{g}=\sum\left(C_{g} * E_{f g} * 10^{-9} * G_{w}\right)
\end{aligned}
$$

$E_{e}$ : GHGs emission by electricity [tCO2eq]

$E_{g}$ : GHGs emission by LNG [ $\left.\mathrm{tCO} 2 \mathrm{eq}\right]$

$C_{e}$ : Electricity consumption [MWh]

$C_{g}$ : Gaseous fossil fuel(LNG) consumption $\left[\mathrm{N} \cdot \mathrm{m}^{3}\right]$

$E_{f e}:$ Emission factor of electricity [tGHGs/MWh]

$E_{f g}:$ Emission factor of LNG $[\mathrm{kgGHGs} / \mathrm{TJ}]$

$G_{w}:$ Global warming potential

In the case of electricity, it was assumed that the consumptions before and after the CHP installation were the same, and accordingly GHGs emission caused by the use of electricity were the same before and after adopting CHP. However, as the emission factors between the electricity generation phase and the use phase are different, GHGs emission each in the generation phase and the use phase were calculated respectively.

As for LNG, LGN consumption of the existing boiler and CHP were used to calculate GHGs emission. And GHGs emission occurring from CHP generation are added to the emission caused by the use of LNG

\section{Comparison of GHGs emission in winter depending on heating load sharing rates of $\mathrm{CHP}$}

Because the energy consumption rate by LNG is high in winter, the CHP generation amount was calculated based on the LNG consumptions. For accurate comparison, the heating load sharing rate of CHP according to heat use 
was applied in the $10 \%$ unit to calculate the CHP generation amount. Boiler efficiency used to calculate the heat generation amount based on the amount used was

Table 3. Comparison of GHGs emission depending on heating sharing rates of CHP

[Unit : $\left.\mathrm{tCO}_{2} \mathrm{eq}\right]$

\begin{tabular}{|l|r|r|r|r|c|}
\hline & Electricity generation & Electricity use & LNG use & \multicolumn{1}{c|}{ Total } & Reduction rate [\%] \\
\hline CHP [100\%] \& Boiler [0\%] & 0 & 10,925 & 12,378 & 23,304 & 12.2 \\
\hline CHP [90\%] \& Boiler [10\%] & 238 & 10,925 & 11,650 & 22,813 & 14.0 \\
\hline CHP [80\%] \& Boiler [20\%] & 1,381 & 10,925 & 10,921 & 23,227 & 12.5 \\
\hline CHP [70\%] \& Boiler [30\%] & 2,523 & 10,925 & 10,193 & 23,642 & 10.9 \\
\hline CHP [60\%] \& Boiler [40\%] & 3,666 & 10,925 & 9,465 & 24,056 & 9.4 \\
\hline CHP [50\%] \& Boiler [50\%] & 4,808 & 10,925 & 8,736 & 24,470 & 7.8 \\
\hline CHP [40\%] \& Boiler [60\%] & 5,951 & 10,925 & 8,008 & 24,884 & 6.2 \\
\hline CHP [30\%] \& Boiler [70\%] & 7,094 & 10,925 & 7,279 & 25,298 & 4.7 \\
\hline CHP [20\%] \& Boiler [80\%] & 8,236 & 10,925 & 6,551 & 25,712 & 3.1 \\
\hline CHP [10\%] \& Boiler [90\%] & 9,379 & 10,925 & 5,822 & 26,126 & 1.6 \\
\hline CHP [0\%] \& Boiler [100\%] & 10,521 & 10,925 & 5,094 & 26,540 & 0.0 \\
\hline
\end{tabular}

93.8\% while CHP efficiencies for electricity and heat were $42.1 \%$ and $38.6 \%$ respectively, according to the test results produced by Korea District Heating Corp.

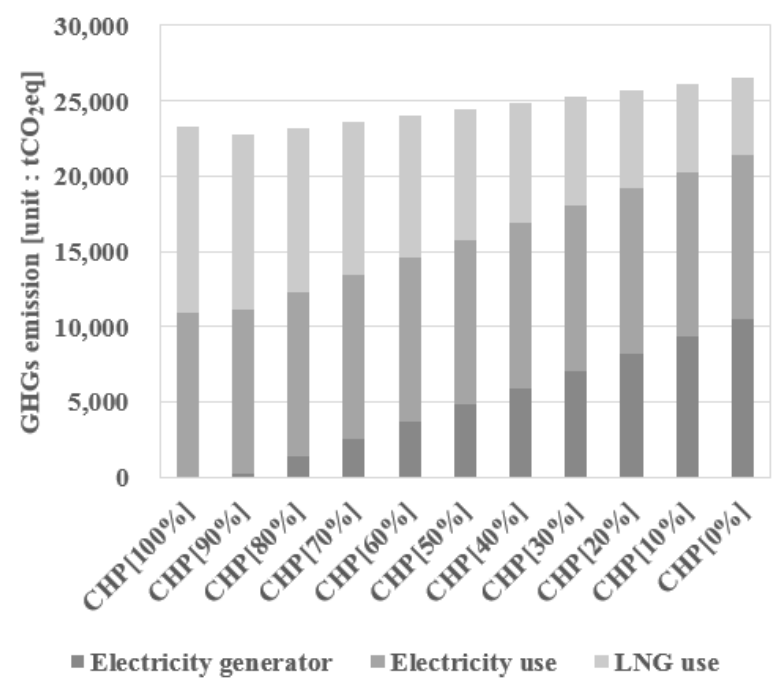

Figure 4. GHGs emission depending on the heating load rate of CHP

Figure 4 shows the GHGs emission depending on the heating load rate of CHP. The analysis results show that, in the electricity use phase, there was no difference in GHGs emission between the existing electricity supply method and the CHP method. Because the amounts of electricity consumed were assumed to be the same in winter, while in the electricity generation phase, GHGs emission were different depending on the heating load sharing rates of CHP. Figure 5 shows GHGs emission reduction rates depending on the load rate of CHP. It shows that at $90 \%$ of the CHP heating load sharing rate, the reduction rate was the highest as $14.0 \%$.

Table 3 shows the comparison of GHGs emission depending on heating sharing rates of CHP and boiler. When heat supply was implemented completely by CHP, generated electricity was 25,804MWh, 2,043MWh more generated than $23,761 \mathrm{MWh}$, the actual amount consumed. The surplus electricity was excluded for calculating GHGs emission. When the heating load sharing rate of CHP was increasing, GHGs emission were decreasing but they rebounded at above $90 \%$. When the heating load sharing rate of CHP was $90 \%$, GHGs emission were at the lowest to $22,813 \mathrm{tCO}_{2} \mathrm{eq}$ and the reduction amount and rate was at the highest to $3,727 \mathrm{tCO}_{2}$ eq and $14.0 \%$, respectively. GHGs emission were low and their reduction rates were high in the order of $80 \%, 100 \%$ and $70 \%$ of the CHP heating load sharing rate.

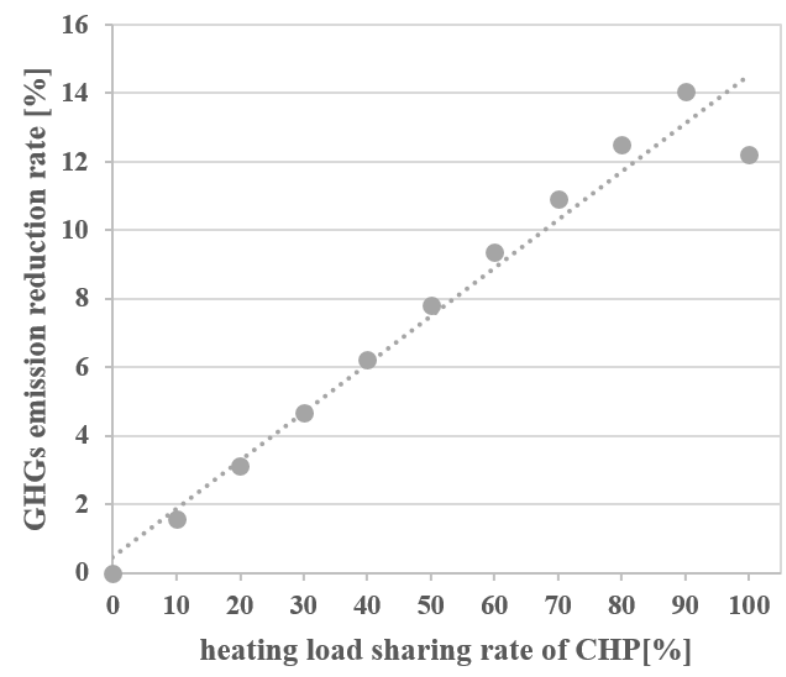

Figure 5. GHGs emission reduction rate depending on the heating load rate of CHP

\section{Conclusion}

This research analyzed the greenhouse gases emission reduction effect by studying $\mathrm{S}$ campus of $\mathrm{K}$ University buildings, which is one of the University that 
implemented the Management of Target for GHGs \& Energy since 2010, as a research subject. Because electricity consumption were assumed the same at before and after the regulation implement, GHGs emission caused by the use of electricity were the same. Thus, GHGs emission occurring from the power generating phase were calculated and added to the total GHGs emission for electricity.

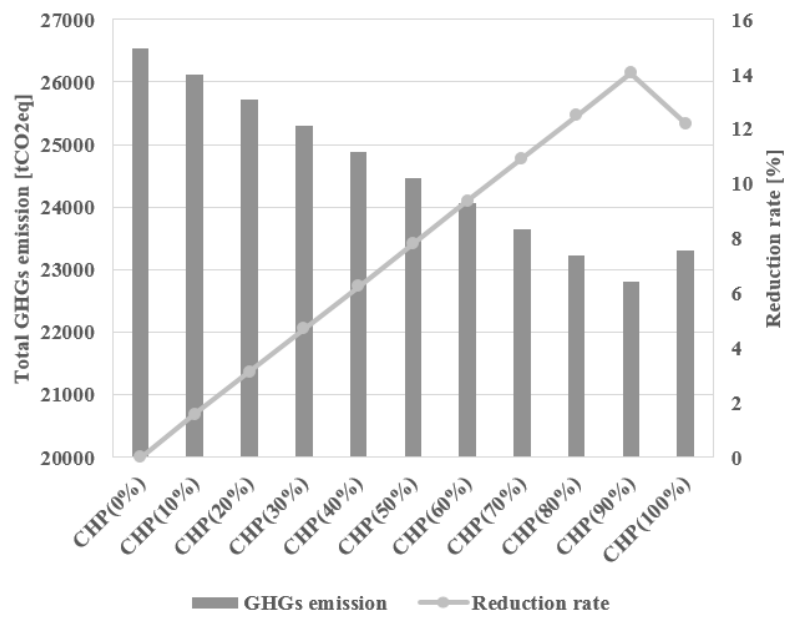

Figure 6. The comparison of GHGs emission and reduction rate depending on heating load rates of CHP and boiler

Figure 6 shows the comparison of GHGs emission and reduction rate depending on heating load rates of CHP and boiler. In this research, GHGs emission varying depending on the heating load sharing rate of CHP were calculated. The increasing heating load sharing rate decreased GHGs emission, but when the sharing rate became over $90 \%$, GHGs emission started to climb. At $90 \%$ of the CHP heating load sharing rate, GHGs emission was the lowest $\left(22,813 \mathrm{tCO}_{2}\right.$ eq $)$ and the reduction rate was the highest $(14.0 \%)$.

In further research, the optimum heating sharing rate to reduce GHGs emission will be calculated by conducting regression analysis based on the GHGs emission according to the CHP heating load sharing rate.

Equations should be centred and should be numbered with the number on the right-hand side.

\section{Acknowledgement}

This work was supported by the National Research Foundation of Korea(NRF) grant funded by the Korea government(MSIP) (NRF-2013R1A2A1A01014020).

\section{References}

1. Paxton K. Giffin, Performance and cost results from a DOE Micro-CHP demonstration facility at Mississippi State University, Energy Conversion and Management, Vol.65, January 2013, pp. 364-371.
2. Osamu Kurata, Norihiko Iki, Takayuki Matsunuma, Tetsuhiko Maeda, Satoshi Hirano, atsuhiko Kadoguchi, Hiromi Takeuchi, Hiro Yoshida, Micro gas turbine cogeneration system with latent heat storage at the University: Part I: Plan and energy flow test, Applied Thermal Engineering, Vol. 65, Issues 1 - 2, pp. 513-523.

3. Osamu Kurata, Norihiko Iki, Takayuki Matsunuma, Tetsuhiko Maeda, Satoshi Hirano, atsuhiko Kadoguchi, Hiromi Takeuchi, Hiro Yoshida, Micro gas turbine cogeneration system with latent heat storage at the University: Part II: Part load and thermal priority mode, Applied Thermal Engineering, Vol. 65, Issues 1-2, 2014, pp. 246-254.

4. Osamu Kurata, Norihiko Iki, Takayuki Matsunuma, Tetsuhiko Maeda, Satoshi Hirano, atsuhiko Kadoguchi, Hiromi Takeuchi, Hiro Yoshida, Micro gas turbine cogeneration system with latent heat storage at the University: Part III: Temperature control schedule, Applied Thermal Engineering, Vol. 70, Issue 1, 2014, pp. 705-715.

5. Byeong-Uk An, Ji-Ae Lee, Youn-Kyu Seo, WonHwa Hong, An Analysis of University's Energy Usage Pattern and Occupancy Satisfaction Survey According to Management of Target for GHGs \& Energy, Journal of Architectural Institute of Korea, Vol. 31, No. 3, 2015, pp.155-162.

6. Byung Ha Kang, Chang Ho Yun, Joon Ahn, Impact of Residential CHP Systems on Greenhouse Gas Emissions in Korea, Korean Journal of AirConditioning and Refrigeration Engineering, Vol. 25, No. 10, 2013, pp.555-561.

7. Seung-Bok Shin, Sooyoung Jun, Ho-Jun Song, Jongjin Park, Sanjeev Maken, Jin-Won Park, Study of fuel cell CHP-technology on electricity generation sector using LEAP-model, Journal of Energy Engineering, Vol. 18, No. 4, 2009, pp.230-238.

8. Information on http://www.kdhc.co.kr

9. Information on http://www.low.go.kr

10. Information on http://www.kpx.or.kr 